\title{
$p$-NİTRO FENOLÜN KALİKSAREN TEMELLİ GRAFEN OKSİT İLE SULU ÇÖZELTİLERDEN UZAKLAŞTIRILMASI
}

\author{
${ }^{1}$ Fatih ÇENGEL ${ }^{(i)},{ }^{2}$ Farabi TEMEL \\ Konya Teknik Üniversitesi, Mühendislik ve Doğa Bilimleri Fakültesi, Kimya Mühendisliği Bölümü, Konya, \\ TÜRKIYE \\ ${ }^{1}$ fatihcengel26@gmail.com, 2ftemel@ktun.edu.tr
}

(Geliş/Received: 22.10.2021; Kabul/Accepted in Revised Form: 11.11.2021)

ÖZ: Bu çalışmada, kaliks[4]aren temelli grafen oksit (GO-Epoksi-C[4]CN), öncelikle grafit tozundan Hummers metodu kullanarak grafen oksitin (GO) sentezlenmesi ve (3-glisidoksipropil)trimetoksisilan (GPTMS) ile etkileştirilerek epoksi ucundan $p$-ter-bütilkaliks[4]aren dinitril türevinin bağlanması ile elde edildi. Sentezlenen bileşiklerin karakterizasyonları, ${ }^{1} \mathrm{H}$ NMR ve FTIR analizleri ile gerçekleştirildi. Elde edilen yeni adsorban (GO-Epoksi-C[4]CN), atık sulardan $p$-nitro fenolün (PNF) giderilmesi için kullanıldı. Öncelikle, adsorban ve başlangıç bileşikleri kullanılarak karşılaştırma çalışmaları gerçekleştirildi ve \% 81 adsorpsiyon verimi ile diğerlerine göre oldukça yüksek bir verim sağladığı gözlendi. Çalışmanın devamında, $\mathrm{pH}$ ve konsantrasyonun adsorpsiyona etkisi incelendi. Konsantrasyon çalışmalarından elde edilen bulgular ışığında adsorpsiyonun Langmuir izotermiyle daha uyumlu olduğu görüldü.

Anahtar Kelimeler: Adsorpsiyon, Kaliksaren, Grafen oksit, p-Nitro fenol

\section{Removal of $p$-Nitrophenol from Aqueous Solutions by Calixarene based Graphene Oxide}

\begin{abstract}
In this study, calix[4]arene-based graphene oxide (GO-Epoxy-C[4]CN) was synthesized using graphene oxide (GO), which was obtained from graphite powder by the Hummers method. After GO preparation, it was reacted by (3-glycidyloxypropyl)trimethoxysilane (GPTMS) to get its epoxy (GOEpoxy). Then, GO-Epoxy-C[4]CN was obtained by immobilization of $p$-tert-butylcalix[4]arene nitrile derivative onto the GO-Epoxy. Characterizations of synthesized compounds were performed by ${ }^{1} \mathrm{H}$ NMR and FTIR analysis. The obtained new adsorbent (GO-Epoxy-C[4]CN) was used for the removal of $p$-nitrophenol (PNP) from wastewater. First of all, comparison studies were carried out using adsorbent and starting compounds, and it was observed that it provided a very high efficiency with $81 \%$ adsorption efficiency compared to the others. Then, the effect of $\mathrm{pH}$ and concentration on adsorption was investigated. Hence, it was seen that the adsorption was more compatible with the Langmuir isotherm.
\end{abstract}

Keywords: Adsorption, Calixarene, Graphene oxide, p-Nitro phenol

\section{GİRIŞ (INTRODUCTION)}

Son zamanlarda teknolojik ilerlemelerin getirmiş olduğu birçok faydanın yanı sıra çevre kirliliğinde ki artış da araştırmacıları bu konularda yoğun çalışmalara yönlendirmiştir. Çevre kirliliğine sebep olan kimyasal bileşiklerin yol açtığı etkiler daha fazla endişe verici hale gelmeye başlamıştır. Fenol ve fenolik bileşikler, toksik oldukları ve canlıların üzerinde kısa ve uzun vadeli sonuçları olduğu için büyük endişe duyulan başlıca kimyasallar arasında yer almaktadır (Mahugo-Santana ve ark., 2010). 
Su kirliliği tarımsal, endüstriyel ve evsel atıkların arıtılmadan derelere, nehirlere ve denizlere deşarjından kaynaklı olarak oluşmaktadır. Teknolojinin gelişmesiyle endüstriyel atıkların artması çevre kirliliğini de arttırmaktadır. Fenolik kirlilik içeren başlıca atık su kaynakları, kimya ve ilaç endüstrileridir. Bu tür atıklarla ilişkili diğer endüstriler reçine üretim endüstrileri, kömür gazlaştırma prosesleri, boya imalatı, petrol rafinerileri ve petrokimya endüstrileridir (Abbas ve ark., 2019). Fenol ve türevleri içeren atık suların biyolojik olarak çevreye olumsuz etkileri vardır. Amerika Çevre Koruma Ajansı'na göre fenolik bileşikler, kirletici olarak 126 kimyasal arasında 11. sırada yer almaktadırlar (Caturla ve ark., 1988).

Endüstriyel atık sulardaki fenolik hidrokarbonlar gibi organik kirliliklerin giderilmesi oldukça zor bir işlemdir. Bu amaçla kimyasal oksidasyon (Wang ve ark., 2021), solvent ekstraksiyonu (Aydın ve Özcan, 2005; Temel, 2020) ve adsorpsiyon (Aladağlı ve ark., 2015; Dogan ve ark., 2020; Akceylan ve ark., 2021) gibi birçok arıtma teknolojisi kullanılmaktadır. Bu yöntemler arasında, adsorpsiyon yöntemi kolay uygulanabilirliği ve ucuz olması gibi avantajları nedeniyle kirlilik giderme çalışmalarında sıkça kullanılmaktadır. Kirliliğin giderilmesi için doğal ya da sentetik adsorban malzemeler hazırlanabilir. Adsorpsiyon çalışmaları için, sentetik malzemeler olarak farklı fonksiyonel grupları olan yeni moleküller sentezlenmektedir. Bu sentetik bileşik gruplarından birisi de kaliksaren türevleridir. Kaliksaren türevleri kolay türevlendirilebilme kabiliyetleri ve kendisine has üç boyutlu yapıları ile birçok uygulamada kullanılmaktadır (Özçelik ve ark., 2019). Hazırlanan bu sentetik moleküllerin adsorpsiyon çalışmaları için bir destek malzemesine immobilizasyonu gerçekleştirilerek elde edilen adsorban ile sulu ortamdan kirlilik uzaklaştırılabilmektedir (Temel ve ark., 2020).

Fenolik kirleticilerin adsorpsiyon çalışmalarında, grafen bazlı kompozitler kullanılmaktadır. Grafen oksit (GO), grafenin oksidatif bir formudur. Fenolik bileşiklerle $\pi-\pi$ etkileşimleri oluşturabilecek sp ${ }^{2}$ hibritleşmesi olan karbon atomlarının varlığı, verimi artırabilecek bir avantaj sağlar (Zhao ve ark., 2021). $\mathrm{Bu}$ nedenle, kaliksaren türevlerinin kendine has adsorpsiyon kapasitelerinin yanında GO ile desteklenmesi daha verimli adsorbanların sentezlenmesini sağlayacaktır.

$\mathrm{Bu}$ çalışmada, kaliks[4]aren temelli grafen oksit (GO-Epoksi-C[4]CN), öncelikle grafit tozundan Hummers metodu kullanarak grafen oksitin (GO) sentezlenmesi ve (3-glisidoksipropil)trimetoksisilan (GPTMS) ile etkileştirilerek epoksi ucundan $p$-ter-bütilkaliks[4]aren dinitril türevinin bağlanması ile elde edildi. Sentezlenen bileşiklerin karakterizasyonu, ${ }^{1} \mathrm{H}$ NMR ve FTIR analizleri ile gerçekleştirildi. Elde edilen yeni adsorban (GO-Epoksi-C[4]CN), atık sulardan $p$-nitro fenolün (PNF) giderilmesi için kullanıldı. Öncelikle, adsorban ve başlangıç bileşikleri kullanılarak karşılaştırma çalışmaları gerçekleştirildi. Ayrıca, $\mathrm{pH}$ ve konsantrasyonun adsorpsiyona etkisi incelendi. Elde edilen veriler Langmuir ve Freundlich adsorpsiyon modellerine uyguland.

\section{MATERYAL VE YÖNTEM (MATERIAL AND METHOD)}

Kimyasallar ve Cihazlar (Chemicals and Instrumentations)

Grafit tozu $(16-60 \mu \mathrm{m})$ chem pure firmasından, sülfürik asit $\left(\mathrm{H}_{2} \mathrm{SO}_{4}, \geq \% 97,0\right)$, fosforik asit $\left(\mathrm{H}_{3} \mathrm{PO}_{4}=\right.$ $\% 85,0)$, potasyum permanganat $\left(\mathrm{K}_{2} \mathrm{MnO}_{4}, \geq \% 99,0\right)$ hidrojen persoksit $\left(\mathrm{H}_{2} \mathrm{O}_{2},=\% 30,0\right)$, hidroklorik asit $(\mathrm{HCl},=\% 37,0), p$-nitro fenol $(\mathrm{PNF}, \geq \% 99,0)$ ve çözücüler ise Merck yada Aldrich firmasından temin edildi. Alınan ürünler analitik saflıkta olup, herhangi bir saflaştırma işlemine tabi tutulmadan kullanıldı.

Sentezlenen bileşiklerin karakterizasyonunda farklı spektroskopik metotlar uygulandı. Öncelikle, reaksiyon süreçleri silika jel kaplı alüminyum tabaka $\left(\mathrm{SiO}_{2}\right.$, Merck $\left.\mathrm{F}_{254}\right)$ kullanılarak ince tabaka kromatografisi (TLC) ile takip edildi. ${ }^{1} \mathrm{H}$ NMR spektrumları Varian $400 \mathrm{MHz}$ NMR spektrometresi ile ve IR spektrumları ise PerkinElmer 100 FTIR spektrometresi ile alındı.

\section{Kaliksaren Moleküllerinin Sentezi (Synthesis of Calixarene Molecules)}

Kalik[4]aren bileşiklerinin başlangıç bileşiği olan, $p$-ter-bütilkaliks[4]aren bileşiği, $p$-ter-bütilfenolün formaldehit ile bazik ortamda kondenzasyon reaksiyonu ile elde edildi (Gutsche ve Iqbal, 1990). 
Kaliks[4]aren dinitril türevi $(\mathrm{C}[4]-\mathrm{CN})$ ise, $p$-ter-bütilkaliks[4]aren bileşiği ile klorasetonitrilin, NaI varlığında asetonitril ortamında reaksiyonu ile elde edildi (Collins ve ark., 1991) (Şekil 1).

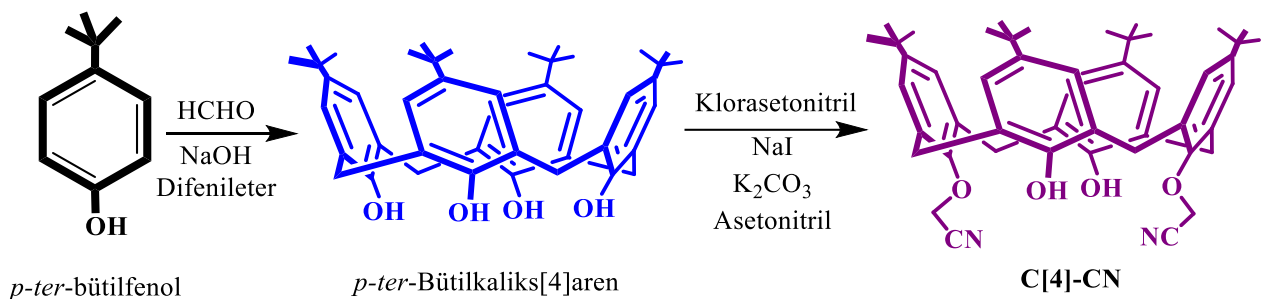

Şekil 1. Kaliks[4]aren türevlerinin sentezi

Figure 1. Synthesis of calix[4]arene derivatives

\section{Grafen Oksit (GO) Sentezi (Synthesis of Graphene Oxide (GO))}

GO sentezi için modifiye Hummers yöntemi kullanıldı (Hummers ve Offeman, 1958; Zaaba ve ark., 2017). GO sentezi için bilinen diğer yöntemlere göre modifiye Hummers yöntemi daha basit, düşük maliyetli, daha tehlikesiz ve daha çevre dostu bir yöntem olduğu için tercih edildi.

Sentezin ilk aşamasında $30 \mathrm{~mL} \mathrm{H}_{2} \mathrm{SO}_{4}$ ve $3,3 \mathrm{~mL} \mathrm{H}_{3} \mathrm{PO}_{4} 30$ dakika buz banyosunda karıştırılmış ve ortama $1 \mathrm{~g}$ grafit tozu eklendi. Daha sonra, hazırlanan reaksiyon ortamına, 6 g $\mathrm{K}_{2} \mathrm{MnO}_{4}$ yavaşça eklendikten sonra $30 \mathrm{dk}$ karıştırıldı. Bu aşamada sıcaklığın $5^{\circ} \mathrm{C}^{\prime} ı$ üzerine çıkmamasına dikkat edildi ve karışımın mor renkten yeşile döndüğ̈ gözlendi. $35^{\circ} \mathrm{C}$ sıcaklıkta 2 saat rengi koyu kahverengiye dönünceye kadar karıştırıldı. Reaksiyon işlemini sonlandırmak için ortama $100 \mathrm{~mL}$ saf su ve $10 \mathrm{~mL}$ hidrojen peroksit yavaşça potasyum permanganat reaksiyonunu durdurmak için eklendi. Karışım bir gece bekletildikten sonra asitliği giderilene kadar saf su ile yıkanarak, santrifüjlendi. Daha sonra etüvde kurutuldu ve toz halinde GO elde edildi (Bai ve ark., 2021) (Şekil 2).

\section{GO-Epoksi-C[4]CN'nin Sentezi (Synthesis of GO-Epoxy-C[4]CN)}

Hazırlanan GO destek malzemesine sentezlenmiş kaliks[4]aren dinitril (C[4]-CN) türevinin bağlanması için öncelikle, 0,5 g GO'nun, $50 \mathrm{~mL}$ toluen içerisinde $30 \mathrm{dk}$ boyunca ultrasonik banyo içerisinde dağılımı sağlandı. Ardından, ortama epoksi türevi olan (3-glisidoksipropil)trimetoksisilan (GPTMS)'den 0,5 mL kadar eklendi ve 24 saat kaynatıldı. Reaksiyon ortamı süzüldü, toluen ve aseton ile yıkanarak, etüvde bir gece boyunca kurutuldu ve GO-Epoksi nanokompozit elde edildi (Rezania ve ark., 2021).

Elde edilen nanokompozit destek maddesi üzerine kaliks[4]aren dinitril türevinin immobilizasyonu için, 0,5 g C[4]-CN ve 0,025 g NaH $50 \mathrm{~mL}$ toluen içerisinde azot atmosferinde $80^{\circ} \mathrm{C}$ 'da, $30 \mathrm{dk}$ karıştırıldı. Reaksiyona 1,5 g GO-Epoksi ve 0,25 g tetrabütilamonyum bromür (TBAB) eklendi ve ortam 24 saat kaynatıldı. Reaksion sonunda, karışım süzülerek toluen, aseton, saf su, DMF ile yıkanarak, etüvde kurutuldu ve 0,25 g GO-Epoksi-C[4]CN elde edildi (Dolaksiz ve ark., 2018). 


\section{Grafit}

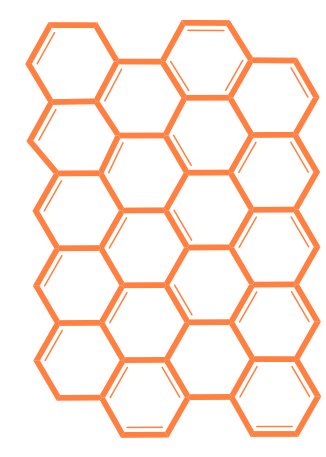

Grafen Oksit (GO)

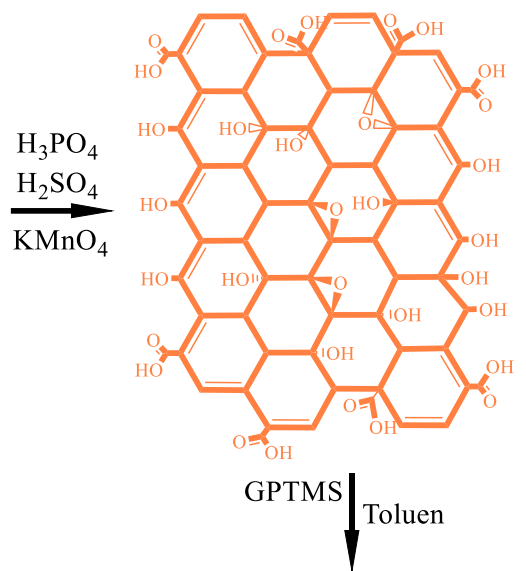

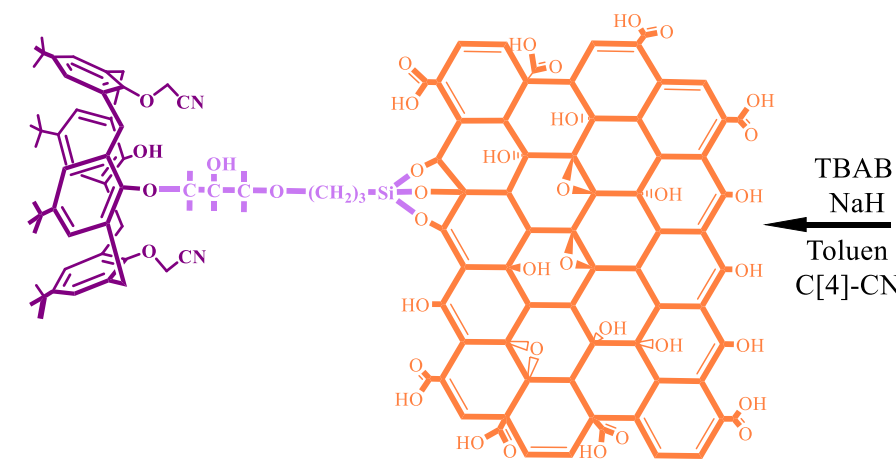

GO-Epoksi-C[4]CN

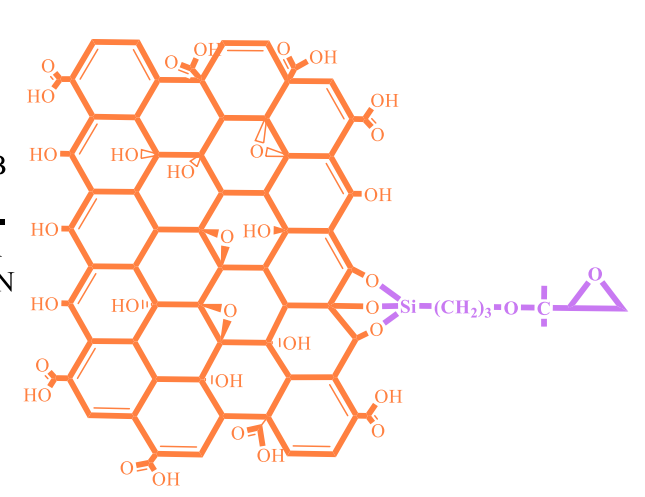

GO-Epoksi

Şekil 2. GO-Epoksi-C[4]CN sentezi.

Figure 2. Synthesis of GO-Epoxy-C[4]CN.

\section{Katı-Sıvı Adsorpsiyon Çalışmaları (Solid-Liquid Adsorption Studies)}

Adsorpsiyon deneylerinde, 0,010 g GO-Epoxy-C[4]CN ve $10 \mathrm{~mL}$ PNF çözeltisi (5x10-5 M), 50 mL'lik erlen içerisine alınarak $25^{\circ} \mathrm{C}$ 'da $300 \mathrm{rpm}$ dönüş hızında 1 saat etkileştirilerek, santrifüjlendi ve sulu faz ayrıldı. Adsorpsiyon öncesi ve sonrası, sulu fazda bulunan PNF konsantrasyonları UV-Vis spektrofotometresiyle tayin edildi. Ortam pH'ına göre PNF, fenol ya da fenolat anyonu formunda bulunduğu için asidik ve bazi duruma göre değişen sprektumlarda, spektrumların kesiştiği nokta olan izosbestik noktada (348 nm) \% adsorpsiyon değerleri ölçüldü (Peng ve ark., 2016). Yüzde adsorpsiyon verimi (\%A) şu şekilde hesaplandı:

$$
A \%=\left[\left(A_{o}-A\right) / A_{o}\right] \times 100
$$

Burada $A_{o}$ ve $A$, sırasıyla PNF'nin adsorpsiyon öncesi ve sonrası konsantrasyonlarını işaret etmektedir.

\section{BULGULAR (RESULTS)}

\section{Sentez ve Karakterizasyon (Synthesis and Characterizations)}

Bu çalışmada, GO-Epoksi-C[4]CN adsorbanının sentezlenmesi için öncelikle, kaliks[4]aren türevleri sentezlenerek karakterizasyonları ${ }^{1} \mathrm{H}$ NMR ile gerçekleştirildi. $p$-ter-Bütil-kaliks[4]aren, literatüre göre asetonitril ortamında NaI varlığında kloroasetonitril ile etkileştirilerek C[4]-CN (p-ter-bütilUKMK2020: 14. Ulusal Kimya Mühendisliği Kongresi'nde sunulan bildiriler arasından seçilmiştir. 
kaliks[4]arenin nitril türevi) elde edildi. C[4]-CN bileşiğine ait ${ }^{1} \mathrm{H}$ NMR spektrumu Şekil 3'de verildi. Bileşiğin oluşumu ${ }^{1} \mathrm{H}$ NMR'da (Şekil 3) ter-bütil gruplarının 0.88 ve 1.32 ppm'de iki ayrı sinyal olarak gözlenmesi ve moleküldeki $-\mathrm{CH}_{2} \mathrm{CN}$ grubuna ait protonların sinyallerinin, $4.82 \mathrm{ppm}$ de bir singlet şeklinde ortaya çıkmasıyla doğrulandı. Daha sonra, GO modern Hummers yöntemi ile sentezlendi. GO'nun varlığı, UV-Vis spektrometresi ve FTIR spektrumu ile analiz edildi (Şekil 4). Şekil 4a'da, GO için karakteristik dalga boyu $238 \mathrm{~nm}$ olarak görüldü (Saxena ve ark., 2011; Johra ve ark., 2014). FTIR spektrumunda, $3250 \mathrm{~cm}^{-1}$ bölgesindeki güçlü ve geniş band yapıdaki O-H gerilme titreşimlerini temsil eder. $1685 \mathrm{~cm}^{-1}$ de görülen pik ise, yapıdaki $\mathrm{C}=\mathrm{O}$ grubuna ait geril bandını ifade eder. $\mathrm{sp}^{2}$ hibritleşmesi yapan $C=C$ bağlarına ait düzlem içi titreşimler ise $1603 \mathrm{~cm}^{-1}$ de görüldü. $1396 \mathrm{~cm}^{-1}$ de görülen pik, $C-O H$ deformasyon titreşim bandını işaret etti. Son olarak, C-O gerilme titreşimleri ise $1041 \mathrm{~cm}^{-1} \mathrm{de}$ gözlendi (Çiplak ve ark., 2015). GO-Epoksinin yapısı da 700-1200 $\mathrm{cm}^{-1}$ aralığındaki geniş bandın sebebi olan GO ve GPTMS'nin reaksiyonu sonucu oluşan Si-O-C bağlarının karakteristik eğilme titreşimi ve simetrik gerilme titreşimlerinin varlığıyla doğrulandı. Ayrıca, 2885 ve $2978 \mathrm{~cm}^{-1}$ deki pikler ise GPTMS'nin yapısındaki alkil zincirlerini işaret etti (Dun ve Zuo, 2017).

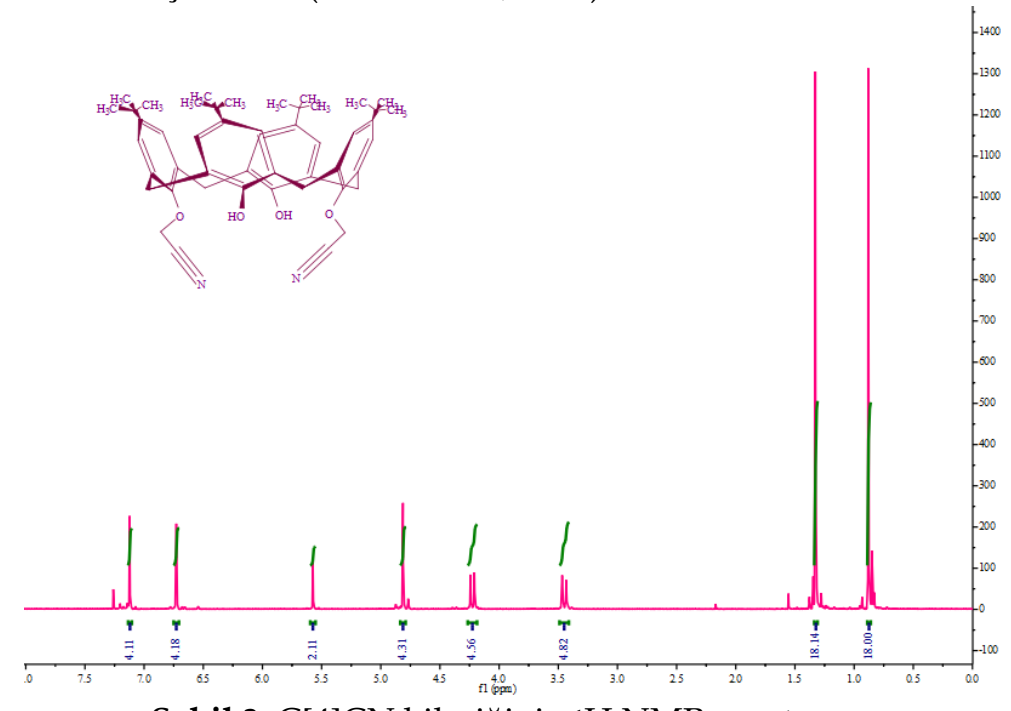

Şekil 3. C[4]CN bileşiğinin ${ }^{1} \mathrm{H}$ NMR spectrumu.

Figure 3. ${ }^{1} \mathrm{H}$ NMR spectra of $C[4] C N$ compound. 

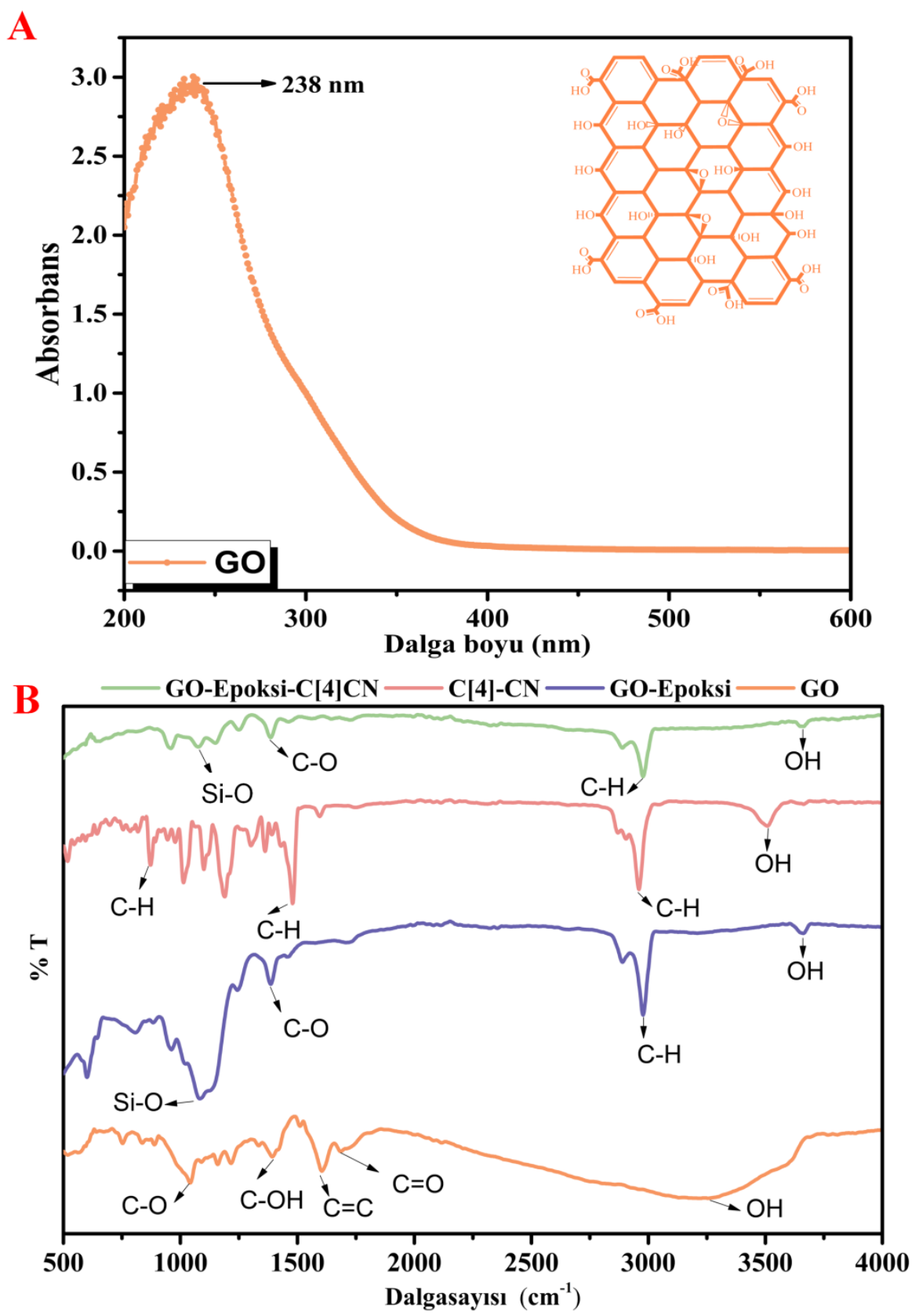

Şekil 4. A) GO'e ait UV-Vis spektrumu, B) Sentezlenen bileşiklere ait FT-IR spektrumları.

Figure 4. A) UV-Vis spectrum of GO, B) FT-IR spectrums of synthesized compounds.

\section{Katı-Sıvı Adsorpsiyon Çalışmaları (Solid-Liquid Adsorption Studies)}

Sentezlenen adsorbanın PNF'ye karşı adsorpsiyon özelliklerini incelemek için katı-sıvı adsorpsiyon

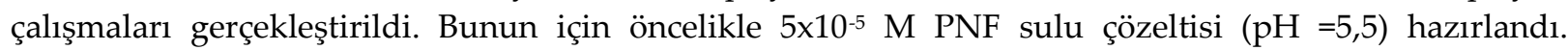
Hazırlanan adsorbanın, başlangıç bileşiklerine göre adsorpsiyon özelliklerini incelemek için karşılaştırma deneyleri PNF çözeltisinde herhangi bir $\mathrm{pH}$ değişikliği yapılmadan, 25 mg adsorban dozajı kullanılarak 300 rpm dönüş hızında 1 saat süresince kesikli katı-sıvı adsorpsiyon (batch type adsorption) şeklinde gerçekleştirildi ve elde edilen UV-Vis spektrumuna ait sonuçlar Şekil 5'de verildi. Deneylerde başlangıç malzemeleri olan GO, GO-Epoksi ve GO-Epoksi-C[4]CN adsorbanı kullanıldı. GO partikülleri çözelti içerisinde dağıldığı için yüksek absorbans verdi ve adsorpsiyon çalışması için uygun bir sonuç alınamadığı için bu haliyle adsorban olarak kullanımının mümkün olmayacağı anlaşıldı. GO'nun epoksi 
ile bağlanması, silika destekli bir karakter sergilemesini ve adsorban olarak kullanılabilmesini sağladı. Böylece, GO-Epoksi türevi \% 35 adsorpsiyon verimi gösterirken, GO-Epoksi-C[4]CN ise \% 81 verimle iyi bir sonuç ortaya koydu. C[4]CN bileşiğinin adsorpsiyon verimini önemli ölçüde artırdığı görüldü. GO'nun epoksi ile desteklenmesi ve kaliks[4]aren gibi adsorpsiyon konusunda iyi sonuçlar veren bir bileşiğin kullanımı ile sulu ortamdaki PNF'nin adsorban yüzeyine adsorbe olması yüksek verimle gerçekleşmiş oldu. Çizelge 1'de elde edilen \% adsorpsiyon verimler ile literatürdeki çalışmalar karşılaştırıldı. Bu sonuçlara göre, önerilen adsorbanın literatürde kullanılan bir çok adsorban ile karşılaştırılabilir performans sergilediği görüldü. Adsorbanın yüksek verimlilik göstermesi nedeniyle $\mathrm{pH}$ ve konsantrasyon gibi farklı parametre çalışmalarına devam edildi.

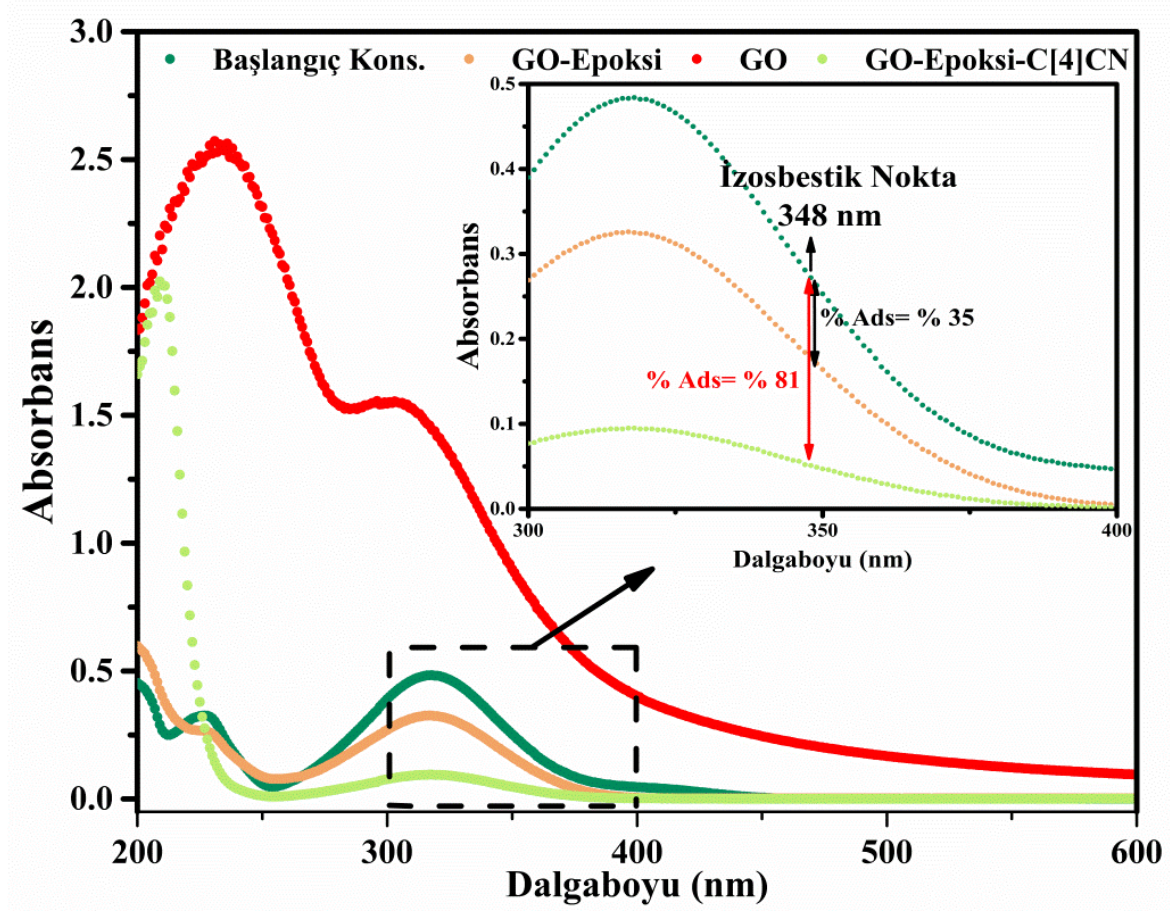

Şekil 5. GO, GO-Epoksi ve GO-Epoksi-C[4]CN'nin PNF adsorpsiyon spektrumları (Adsorpsiyon koşulları: $5 \times 10^{-5} \mathrm{M}$ PNF, $25 \mathrm{mg}$ adsorban, $25^{\circ} \mathrm{C}$ ve 1 saat)

Figure 5. PNP adsorption spectrums of GO, GO-Epoxy and GO-Epoxy-C[4]CN (Adsoorption conditions: 5x10-5 M PNP, $25 \mathrm{mg}$ adsorbent, $25^{\circ} \mathrm{C}$ and $\left.1 \mathrm{~h}\right)$

Çizelge 1. PNF giderimi için literatürdeki kesikli adsorpsiyon verimleri. Table 1. Batch-type adsorption efficiency in the literature for removal of PNP.

\begin{tabular}{cccc}
\hline Yöntem & Adsorban & \% Ads & Ref. \\
\hline Kesikli adsorpsiyon & C[4]APS & 76 & (Aladağlı ve ark., 2015) \\
Kesikli adsorpsiyon & C[4]BS & 23,5 & (Dolaksiz ve ark., 2018) \\
Kesikli adsorpsiyon & C[6]TS & 83 & (Dogan ve ark., 2020) \\
Kesikli adsorpsiyon & K[9]BMN & 7.86 & (Akceylan ve ark., 2021) \\
Kesikli adsorpsiyon & CAC-250 & 77 & (Yadav ve ark., 2020) \\
Kesikli adsorpsiyon & L.MWNTs-10 & 80.5 & (Yao ve ark., 2014) \\
Kesikli adsorpsiyon & GO-Epoksi-C[4]CN & $\mathbf{8 1}$ & Bu çalışmada \\
\hline
\end{tabular}

\section{pH Etkisi (Effect of pH)}

Çözelti pH'sı, adsorpsiyon çalışmaları için pH'a bağlı olarak PNF'nin fenol ya da fenolat gibi her iki formda da bulunması nedeniyle çok önemli bir parametredir. Bu nedenle, pH'nin etkisini görmek için 
GO-Epoksi-C[4]CN üzerine PNF'nin adsorpsiyonu 2 ile $8 \mathrm{pH}$ aralığında $(2,36,4,22,6,39,6,92$ ve 7,21 olarak) incelendi. Önceki parametrelerden farklı olarak adsorban dozajı $10 \mathrm{mg}$ alındı, PNF çözelti

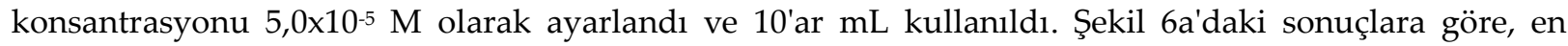
yüksek PNF adsorpsiyonu $\mathrm{pH}=2-4$ aralığında gerçekleşti. Bu durum, hem GO-Epoksi-C[4]CN'nin yüzey yüküne davranışına hem de PNF'nin ayrışma kimyasına bağlandı. Adsorban yüzeyinde fazlaca -OH gruplarının bulunması, $\mathrm{pH}$ durumuna göre protonasyon veya deprotonasyonların oluşumuna neden olur. Adsorban yüzeyinin yüksek pH'larda negatif yükleneceği, düşük pH'larda ise gözlenen yüksek adsorpsiyonun ise adsorban yüzeyindeki negatif yüklerin nötralizasyonundan kaynaklanabileceği düşünüldü. PNF'nin pKa değerinin 7,2 olmasından dolayı, PNF molekülleri yüksek pH'larda ayrışma nedeniyle anyonlara dönüşür. Sonuç olarak, yüksek pH'larda adsorban yüzeyinin negatif yüklenmesi ve PNF moleküllerinin anyonlara dönüşmesi adsorban ve adsorbat arasında elektrostatik itmelere neden olacağı belirlendi. Bu durum, hem deneysel sonuçlarda olduğu gibi düşük $\mathrm{pH}$ değerlerinde PNF adsorpsiyonunun daha verimli olacağını gösterdi. Bu nedenle, sonraki çalışmalarda PNF çözelti pH'ları 2 olarak çalışıldı (Lu ve ark., 2016).
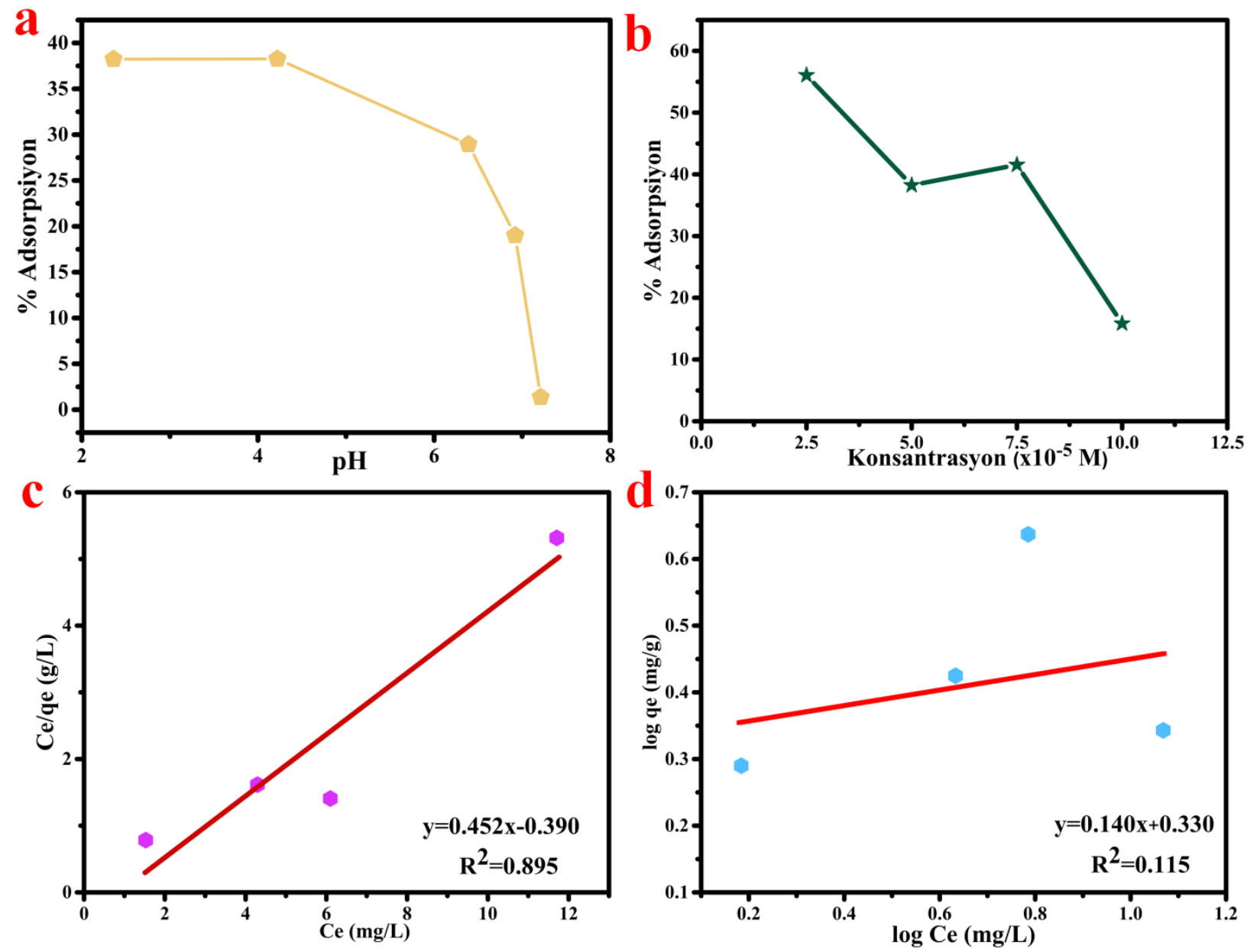

Şekil 6. a) pH etkisi, b) konsantrasyon etkisi, c) Langmuir ve d) Freundlich izotermi sonuçları (Adsorpsiyon koşulları: $10 \mathrm{mg}$ adsorban, $25^{\circ} \mathrm{C}$ ve 1 saat)

Figure 6. a) $\mathrm{pH}$ effect, $\boldsymbol{b}$ ) concentration effect, $\boldsymbol{c}$ ) Langmuir, and $\boldsymbol{d}$ ) Freundlich isotherm results (Adsoorption conditions: $10 \mathrm{mg}$ adsorbent, $25^{\circ} \mathrm{C}$ and $\left.1 \mathrm{~h}\right)$

\section{PNF Konsantrasyonunun Etkisi (Effect of PNP Concentration)}

Başlangıç konsantrasyonunun adsorpsiyonu üzerine etkisini araştırmak için, farklı konsantrasyonlarda PNF çözeltileri $\left(2,5 \times 10^{-5}, 5 \times 10^{-5}, 7,5 \times 10^{-5}, 1 \times 10^{-4} \mathrm{M}\right)$ hazırland1. Adsorpsiyon deneyleri 
$10 \mathrm{mg}$ adsorban dozajı ve $10 \mathrm{~mL}$ PNF çözeltisi kullanılarak $\mathrm{pH} 2,0^{\prime}$ da ve $25^{\circ} \mathrm{C}^{\prime}$ da gerçekleştirildi. Başlangıç PNF konsantrasyonlarına karşı \% adsorpsiyon sonuçları Şekil 6b'de verildi. Sonuçlara göre, adsorpsiyon veriminde başlangıç konsantrasyonundaki artışın aksine azalma gözlendi. Bu durumun, adsorban yüzeyindeki adsorpsiyon bölgelerinin düşük konsantrasyonlarda doygunluğa ulaştığından kaynaklı olduğu düşünüldü. Yüksek başlangıç konsantrasyonları adsorbanın adsorpsiyon kapasitesinin düşmesine neden olduğu anlaşıldı (Dolaksiz ve ark., 2018; Dogan ve ark., 2020). Böylece, düşük konsantrasyonlarda PNF ile GO-Epoksi-C[4]CN arasında güçlü etkileşimlerin gerçekleştiği belirlendi.

\section{Adsorpsiyon İzotermleri (Adsorption Isotherms)}

Adsorpsiyon izotermlerinin deneysel verilerini açıklamak için literatürde birçok model yayınlanmıştır. Bunlar arasında Langmuir ve Freundlich modelleri en sık kullanılan modellerdir. Bu çalışmada, PNF adsorpsiyonu ile çözeltideki denge konsantrasyonu arasındaki ilişkiyi açıklamak için her iki model de kullanıldı.

Langmuir izotermi aşağıda belirtilen eşitlik ile uygulandı (Tabakci, 2008):

$$
C_{e} / q_{e}=\left(1 / q_{0} b\right)+\left(C_{e} / q_{0}\right)
$$

Burada, $C_{e}(\mathrm{mg} / \mathrm{L})$ ve $q_{e}(\mathrm{mg} / \mathrm{g})$ sirasıyla çözeltinin denge konsantrasyonunu ve dengede adsorplanan PNF miktarın ifade eder. $C_{0}$ ve $b$ ise, sırasiyla maksimum adsorpsiyon kapasitesi ve adsorpsiyon enerjisinin bir göstergesidir.

$\mathrm{C}_{\mathrm{e}} / \mathrm{q}_{\mathrm{e}}$ nin Ce'ye karşı çizilen grafiğin eğiminden $q_{0}$, kesişim noktasından ise $b$ sırasıyla, 2,212 mg/g ve $-1,159 \mathrm{~L} / \mathrm{mg}$ olarak bulundu. Sonuçlar Çizelge 2'de verildi.

Freundlich izotermi ise aşağıda belirtilen eşitlik ile uygulandı (Tor ve ark., 2013; Batur ve ark., 2021):

$$
\log q_{e}=\log K_{f}+(1 / n) \log C_{e}
$$

Burada, $K_{f}(\mathrm{mg} / \mathrm{g})$ ve $n$ sirasiyla adsorpsiyon kapasitesinin kabaca bir göstergesini ve adsorpsiyon kapasitesi ve yoğunluğunun bir göstergesi olan ampirik bir parametreyi işaret eder. logqe'nin logCe'ye karşı çizilen grafiğin eğiminden $n$, kesişim noktasından ise $K_{f}$ sırasıyla, 7,148 ve 2,139 mg/g olarak bulundu. Sonuçlar Çizelge 2'de özetlendi.

Çizelge 2. Langmuir ve Freundlich izoterm sabitleri ve korelasyon katsayıları.

\begin{tabular}{|c|c|c|c|}
\hline İzotermler & Model & abitleri & $\mathbf{R}^{2}$ \\
\hline Langmuir & $\mathrm{q}_{0}(\mathrm{mg} / \mathrm{g})=2,212$ & $\mathrm{~b}(\mathrm{~L} / \mathrm{mmol})=-1,159$ & 0,895 \\
\hline Freundlich & $\mathrm{K}_{\mathrm{f}}(\mathrm{mg} / \mathrm{g})=2,139$ & $\mathrm{n}=7,147$ & 0,115 \\
\hline
\end{tabular}
Table 2. Langmuir and Freundlich isotherm constants and correlation coefficients.

Sonuç olarak, $\mathrm{R}^{2}$ değerlerine bakıldığında, sonuçların her iki izoterm için mükemmel bir uyum göstermediği anlaşldı. Fakat Langmuir izoterminin, Freundlich izotermine göre daha uyumlu olduğu görüldü.

\section{Adsorpsiyon Mekanizması (Adsorption Mechanism)}

GO temelli malzemeler birçok kirletici ile çok iyi etkileşebilecek oksijen içerikli gruplara sahiptir (Liao ve ark., 2020). Ayrıca, hem GO yapısındaki hidroksil ve karbonil grupları hem de kaliks[4]aren nitril türevinde bulunan azot atomları, PNF ile güçlü etkileşim yapma potansiyeli vardır (Rezania ve ark., 2021). GO-Epoksi-C[4]CN adsorbanı üzerine PNF'nin adsorpsiyon mekanizması Şekil 7'de gösterildi. Çözeltinin pH'ı pKa'nın ötesine geçtiğinde fenolik bileşiklerin fenolat anyonlarına dönüştüğü bilinmektedir. $\mathrm{Bu}$ nedenle, $\mathrm{pH}=2-4$ aralığında, PNF moleküler formda GO-Epoksi-C[4]CN üzerine adsorbe edildiği düşünüldü. Böylece, hem PNF hem de adsorbanın hidrojen bağ 1 ve elektrostatik etkileşim yapma kabiliyetlerinin, hidrofobik ve van der Waals gibi moleküler etkileşimlerin yanı sıra hidrojen bağ sonucuna varıldı (Dolaksiz ve ark., 2018). 


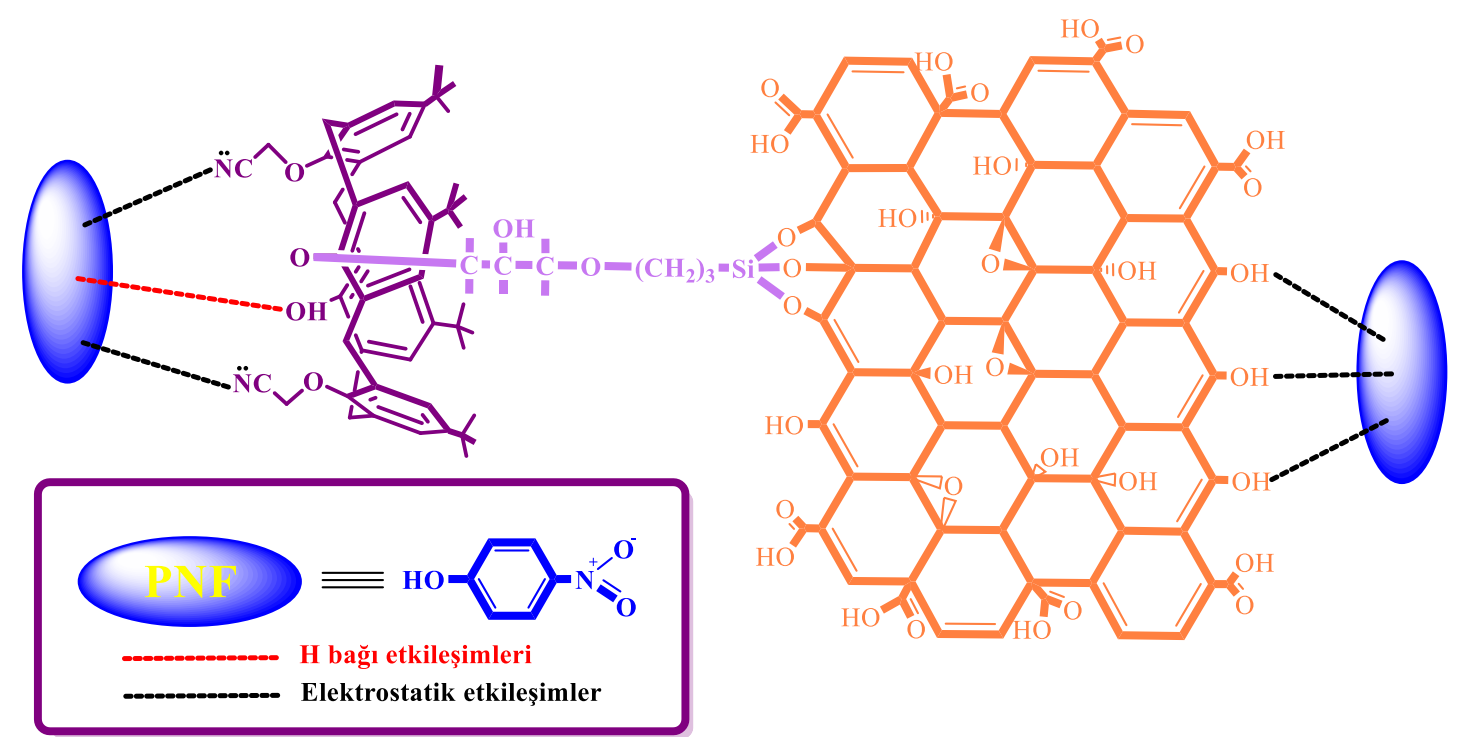

Şekil 7. GO-Epoksi-C[4]CN ile PNF arasında muhtemel elektrostatik ve $\mathrm{H}$ bağı etkileşimleri. Figure 7 Possible electrostatic and hydrogen bond interactions between GO-Epoxy-C[4]CN and PNP.

\section{SONUÇLAR ve DEĞERLENDİRME (RESULTS and DISCUSSIONS)}

Bu çalışmada, kaliksaren temelli grafen oksit adsorbanı hazırlanarak, $p$-nitro fenolün (PNF)'ün sulu çözeltilerden giderim için kullanıldı. Bu amaçla öncelikle, grafit tozundan Hummers metodu kullanarak grafen oksit (GO) sentezlendi ve (3-glisidoksipropil)trimetoksisilan (GPTMS) ile etkileştirilerek epoksi ucundan $p$-ter-bütilkaliks[4]aren dinitril türevinin bağlanması ile GO-Epxy-C[4]CN elde edildi. Sentezlenen bileşiklerin karakterizasyonları, ${ }^{1} \mathrm{H}$ NMR ve FTIR analizleri ile gerçekleştirildi. Başlangıç çalışmalarında, önerilen adsorbanın öncü maddelerine göre oldukça yüksek performans gösterdiği görüldü. Daha sonra, pH ve başlangıç konsantrasyonlarının adsorpsiyon üzerine etkisi incelendi. Adsorpsiyon sonuçlarının, Langmuir izotermiyle daha uyumlu olduğu görüldü. Önerilen adsorban yüzeyine PNF adsorpsiyon mekanizmasının, elektrostatik ve hidrojen bağı etkileşimleri üzerinden ilerlediği bildirildi. Son olarak, bu çalışma ile sulu ortamlardan PNF'nin kaliksaren temelli grafen malzemeler ile yüksek performansla giderilebileceği anlaşıldı.

\section{TEŞEKKÜR (ACKNOWLEDGEMENT)}

Bu çalışma, 10-12 Haziran 2021 tarihleri arasında Konya Teknik Üniversitesi Kimya Mühendisliği Bölümünde gerçekleştirilen 14. Ulusal Kimya Mühendisliği Kongresinde sunulmuş ve ek çalışmalarla bu makaleye dönüştürülmüştür. Bu çalışma için, Konya Teknik Üniversitesi'ne sağlamış olduğu imkanlardan dolayı teşekkür ederiz.

\section{KAYNAKLAR (REFERENCES)}

Abbas, M. N., Al-Madhhachi, A.-S. T. ve Esmael, S. A., 2019, Quantifying soil erodibility parameters due to wastewater chemicals International Journal of Hydrology Science and Technology, 9 (5), 550-568.

Akceylan, E., Erdemir, S., Özçelik, E. ve Tabakc1, B., 2021, Bazı fenolik kirliliklerin imidazol türevli kaliks[4]aren içeren manyetik nanopartiküller kullanarak sulu çözeltilerden uzaklaştırılması, Konya Journal of Engineering Sciences, 9 (2), 442-454.

Aladağll, V., Temel, F. ve Tabakcl, M., 2015, Removal of p-Nitrophenol from Aqueous Solutions Using Aminopropyl Silica Gel-Immobilized Calix[4]Arene Polymer (C[4]APS), Anadolu University Journal of Science and Technology-A Applied Sciences and Engineering, 16 (2), 155. 
Aydın, M. E. ve Özcan, S., 2005, Konya yeraltı sularında klorlu fenoller, Selçuk Üniversitesi Mühendislik, Bilim Ve Teknoloji Dergisi, 20 (1), 9-18.

Bai, L., Tajikfar, A., Tamjidi, S., Foroutan, R. ve Esmaeili, H., 2021, Synthesis of MnFe2O4@graphene oxide catalyst for biodiesel production from waste edible oil, Renewable Energy, 170, 426-437.

Batur, E., Baytar, O., Kutluay, S., Horoz, S. ve Şahin, Ö., 2021, A comprehensive new study on the removal of $\mathrm{Pb}$ (II) from aqueous solution by şırnak coal-derived char, Environ Technol, 42 (3), 505-520.

Caturla, F., Martín-Martínez, J. M., Molina-Sabio, M., Rodriguez-Reinoso, F. ve Torregrosa, R., 1988, Adsorption of substituted phenols on activated carbon, Journal of Colloid and Interface Science, 124 (2), 528-534.

Collins, E. M., McKervey, M. A., Madigan, E., Moran, M. B., Owens, M., Ferguson, G. ve Harris, S. J., 1991, Chemically modified calix[4]arenes. Regioselective synthesis of 1,3-(distal) derivatives and related compounds. X-Ray crystal structure of a diphenol-dinitrile, Journal of the Chemical Society, Perkin Transactions 1 (12), 3137-3142.

Çiplak, Z., Yildiz, N. ve Çalimli, A., 2015, Investigation of Graphene/Ag Nanocomposites Synthesis Parameters for Two Different Synthesis Methods, Fullerenes, Nanotubes and Carbon Nanostructures, 23 (4), 361-370.

Dogan, M., Temel, F. ve Tabakci, M., 2020, High-Performance Adsorption of 4-Nitrophenol onto Calix[6]arene-Tethered Silica from Aqueous Solutions, Journal of Inorganic and Organometallic Polymers and Materials, 30 (10), 4191-4202.

Dolaksiz, Y. E., Temel, F. ve Tabakci, M., 2018, Adsorption of phenolic compounds onto calix[4]arenebonded silica gels from aqueous solutions, Reactive and Functional Polymers, 126, 27-35.

Dun, Y. ve Zuo, Y., 2017, Preparation and characterization of a GPTMS/graphene coating on AA-2024 alloy, Applied Surface Science, 416, 492-502.

Gutsche, C. D. ve Iqbal, M., 1990, p-tert-butylcalix[4]arene, Organic Syntheses, 68, 234.

Hummers, W. S. ve Offeman, R. E., 1958, Preparation of Graphitic Oxide, Journal of the American Chemical Society, 80 (6), 1339-1339.

Johra, F. T., Lee, J.-W. ve Jung, W.-G., 2014, Facile and safe graphene preparation on solution based platform, Journal of Industrial and Engineering Chemistry, 20 (5), 2883-2887.

Liao, C., Zhao, X.-R., Jiang, X.-Y., Teng, J. ve Yu, J.-G., 2020, Hydrothermal fabrication of novel threedimensional graphene oxide-pentaerythritol composites with abundant oxygen-containing groups as efficient adsorbents, Microchemical Journal, 152, 104288.

Lu, M., Cheng, Y., Pan, S.-1. ve Wei, G.-y., 2016, Batch adsorption of p-nitrophenol by ZSM-11: equilibrium, kinetic, and thermodynamic studies, Desalination and Water Treatment, 57 (7), 30293036.

Mahugo-Santana, C., Sosa-Ferrera, Z., Torres-Padrón, M. E. ve Santana-Rodríguez, J. J., 2010, Analytical methodologies for the determination of nitroimidazole residues in biological and environmental liquid samples: A review, Anal Chim Acta, 665 (2), 113-122.

Özçelik, E., Temel, F. ve Tabakcl, M., 2019, Kaliksaren türevi immobilize edilmiş merrifield reçinesi ile kaplı qcm sensöründe sulu ortamda 4-nitrofenol algılanması, Konya Mühendislik Bilimleri Dergisi, 7 (3), 595-603.

Peng, Y., Fu, S., Liu, H. ve Lucia, L. A., 2016, Accurately Determining Esterase Activity via the Isosbestic Point of p-Nitrophenol, 2016, 11 (4), 13.

Rezania, S., Kamboh, M. A., Arian, S. S., Alrefaei, A. F., Alkhamis, H. H., Albeshr, M. F., Cho, J., Barghi, A. ve Amiri, I. S., 2021, Nitrile-calixarene grafted magnetic graphene oxide for removal of arsenic from aqueous media: Isotherm, kinetic and thermodynamic studies, Chemosphere, 268, 129348.

Saxena, S., Tyson, T. A., Shukla, S., Negusse, E., Chen, H. ve Bai, J., 2011, Investigation of structural and electronic properties of graphene oxide, Applied Physics Letters, 99 (1), 013104. 
Tabakci, M., 2008, Immobilization of calix[6]arene bearing carboxylic acid and amide groups on aminopropyl silica gel and its sorption properties for $\mathrm{Cr}(\mathrm{VI})$, Journal of Inclusion Phenomena and Macrocyclic Chemistry, 61 (1), 53-60.

Temel, F., 2020, Merrifield Reçinesine Desteklenmiş Kaliks[4]aren Dinitro Türevinin Sulu Ortamdaki Fenolik Türlere Karşı Ekstraksiyon Özelliklerinin İncelenmesi, Konya Mühendislik Bilimleri Dergisi, 8 (1), 60-70.

Temel, F., Turkyilmaz, M. ve Kucukcongar, S., 2020, Removal of methylene blue from aqueous solutions by silica gel supported calix[4]arene cage: Investigation of adsorption properties, European Polymer Journal, 125, 109540.

Tor, A., Aydin, M. E., Aydin, S., Tabakci, M. ve Beduk, F., 2013, Removal of lindane from an aqueous solution by using aminopropyl silica gel-immobilized calix[6]arene, J Hazard Mater, 262, 656-663.

Wang, H., Li, Z., Zhang, F., Wang, Y., Zhang, X., Wang, J. ve He, X., 2021, Comparison of Ti/Ti4O7, $\mathrm{Ti} / \mathrm{Ti} 4 \mathrm{O} 7-\mathrm{PbO} 2-\mathrm{Ce}$, and $\mathrm{Ti} / \mathrm{Ti} 4 \mathrm{O} 7$ nanotube array anodes for electro-oxidation of $\mathrm{p}$-nitrophenol and real wastewater, Separation and Purification Technology, 266, 118600.

Yadav, N., Narayan Maddheshiaya, D., Rawat, S. ve Singh, J., 2020, Adsorption and equilibrium studies of phenol and para-nitrophenol by magnetic activated carbon synthesised from cauliflower waste, Environmental Engineering Research, 25 (5), 742-752.

Yao, Y.-X., Li, H.-B., Liu, J.-Y., Tan, X.-L., Yu, J.-G. ve Peng, Z.-G., 2014, Removal and Adsorption of pNitrophenol from Aqueous Solutions Using Carbon Nanotubes and Their Composites, Journal of Nanomaterials, 2014, 571745.

Zaaba, N. I., Foo, K. L., Hashim, U., Tan, S. J., Liu, W.-W. ve Voon, C. H., 2017, Synthesis of Graphene Oxide using Modified Hummers Method: Solvent Influence, Procedia Engineering, 184, 469-477.

Zhao, R., Li, Y., Ji, J., Wang, Q., Li, G., Wu, T. ve Zhang, B., 2021, Efficient removal of phenol and pnitrophenol using nitrogen-doped reduced graphene oxide, Colloids and Surfaces A: Physicochemical and Engineering Aspects, 611, 125866. 